\title{
Structure of the Flavin Adduct Formed in the Suicide Reaction of $\alpha$-Hydroxybutynoate with D-Lactate Dehydrogenase ${ }^{\dagger}$
}

\author{
Sandro Ghisla, Steven T. Olson, Vincent Massey,* and Jean-Marc Lhoste
}

ABSTRACT: The $\mathrm{Zn}$-dependent flavoenzyme D-lactate dehydrogenase from Megasphaera elsdenii is irreversibly inactivated by the $D$ form of the suicide substrate 2-hydroxy3-butynoic acid. The process of inactivation involves formation of a new pink chromophore, which can be released in intact form from the protein and which was purified to homogeneity by affinity chromatography. Inactivation involves covalent addition of the suicide substrate to the flavin coenzyme. The optical spectra indicate an elongation of the flavin chromophore, and the chemical reactivity suggests a derivative of reduced flavin. The structure of this adduct was deduced from Fourier transform NMR, from the chemical properties, and from comparison with appropriate models, which were synthesized chemically. This structure involves the covalent linkage of the acetylenic inhibitor to positions $N(5)$ and $C(6)$ of the flavin coenzyme via carbon atoms 2 and 4 of the in-

$\mathbf{S}$ tention as tools for the study of flavoenzyme reaction mechanisms. These substrate analogues carry, in addition to the same functional groups as normal substrates, a function which can be activated to a highly reactive species during catalysis; a specific alkylation of the enzyme active center may then occur. For comprehensive information about the general properties of suicide substrates and their use with flavoenzymes, we refer to the review articles by Walsh (1977, 1978).

In the case of flavoenzymes three types of inactivation have so far been discovered. With monoamine oxidase, the substrate analogue propargylamine reacts with the flavocoenzyme to form a covalent $N(5)$ adduct having a cyanine structure (Chuang et al., 1974; Gaertner et al., 1976; Maycock et al., 1976). Several hydroxyacid oxidases [L-lactate oxidase, Ghisla et al. (1976) and Schonbrunn et al. (1976); D- and L-lactate dehydrogenases, Walsh et al. (1972); L-hydroxyacid oxidase, Cromartie \& Walsh (1975); cytochrome $b_{2}$, Lederer (1974); glycollate oxidase, Jewess et al. (1975)] have been reported to be irreversibly inactivated by 2 -hydroxy-3-ynoic acids. In the case of L-lactate oxidase, the mechanism of inactivation was found to occur through primary formation of a cyclic $\mathrm{N}(5)-\mathrm{C}(4 \mathrm{a})$ adduct of the inactivator to the flavin coenzyme (Ghisla et al. 1976; Schonbrunn et al., 1976) which subsequently decays by hydrolysis of the pyrimidine ring. With cytochrome $b_{2}$ (Lederer, 1974) and glycollate oxidase (G. Fendrich and S. Ghisla, unpublished experiments) the same type of inactivation is probable. The third type of irreversible inactivation is given by substrate analogues such as propar-

\footnotetext{
${ }^{\dagger}$ From Fachbereich Biologie der Universität Konstanz, D775 Konstanz, West Germany (S.G.), The Department of Biological Chemistry, The University of Michigan, Ann Arbor, Michigan 48109 (S.T.O. and V.M), and Institut du Radium, Orsay, France (J. -M.L.). Received March l, 1979; revised manuscript received June 20, 1979. This work was supported by a grant from the Deutsche Forschungsgemeinshaft to S.G. and by a grant from the U.S. Public Health Service, GM 11106, to V.M.
}

hibitor to form an additional fused aromatic ring. The pink adduct can be reconverted to an isoalloxazine chromophore by reduction with borohydride and subsequent reoxidation with oxygen. This new isoalloxazine has the spectral properties of an isoflavin, and it is proposed to carry the moiety of the inactivator molecule as substituent at position $\mathrm{C}(6)$. The structure of the pink chromophore representing a cyclic adduct to the flavin positions $\mathrm{N}(5)$ and $\mathrm{C}(6)$ is compared to that of the adduct obtained from L-lactate oxidase from $M y c o b a c$ terium smegmatis and the $\mathrm{L}$ form of the same inhibitor [C(4a)-N(5) cyclic adduct; Schonbrunn, A., Abeles, R. H., Walsh, C. T., Ghisla, S., Ogata, H., and Massey, V. (1976) Biochemistry 15, 1978]. This comparison allows deductions about the relative orientation of substrate, coenzyme, and active center functional groups in the two enzymes.

gylglycine and vinylglycine, which, however, do not modify the flavin coenzyme but have been found to alkylate amino acid residues in the case of D-amino-acid oxidase (Horiike et al., 1975; Marcotte \& Walsh, 1976; Ronchi et al., 1979) and L-amino-acid oxidase (Marcotte \& Walsh, 1976).

In view of the apparent stereospecificity of adduct formation in the case of several flavoenzymes oxidizing $L-\alpha$-hydroxy acids (Walsh, 1978), it was of interest to investigate whether a similar D-specific flavoenzyme would yield a stereochemically different adduct upon reaction with the same suicide substrate. From an evolutionary point of view one might expect that reactivity occurs at the same face of the flavin and positioning of enzyme functional groups is retained within a class of enzymes catalyzing the same reaction type, but using $L$ or $D$ substrates, and that the substrate substituents not directly involved in the catalytic process might assume enantiomeric positions with respect to the coenzyme. A similar prediction has been put forward by Yon and co-workers (Yon et al., 1977 ) in Kaplan's laboratory, who have noticed that a series of flavin-dependent hydroxylases consistently remove the pro- $R$ hydrogen from the substrate dihydronicotinamide

In the preceding paper (Olson et al., 1979), $\alpha$-hydroxybutynoate $(\alpha \mathrm{HB})^{1}$ was shown to be a suicide substrate for the flavoenzyme $D$-lactate dehydrogenase from the anaerobic bacterium Megasphaera elsdenii. Inactivation was demonstrated to occur via a chemical modification of the flavin coenzyme, yielding a pink flavin adduct unlike any previously observed. The structural elucidation of this adduct is detailed in this paper.

\section{Materials and Methods}

Flavodoxin from $M$. elsdenii was purified as described by Mayhew \& Massey (1969). Flavodoxin apoprotein was

\footnotetext{
${ }^{1}$ Abbreviations used: $\alpha \mathrm{HB}, 2$-hydroxy-3-butynoic acid; $\alpha \mathrm{KB}, 2$ keto-3-butynoic acid; NMR, nuclear magnetic resonance; NOE, nuclear Overhauser effect.
} 
obtained according to the method of Mayhew (1971). Phosphodiesterase, partially purified from Crotalus adamanteus venom, was from Sigma Chemical Co. Alternatively, Naja naja venom was used (Sigma Chemical Co.). Alkaline phosphatase from calf intestine was from Böhringer, acid phosphatase from wheat germ was from Sigma Chemical $\mathrm{Co}_{0}$., and sodium borodeuteride, dimethyl $-d_{6}$ sulfoxide, and $\mathrm{D}_{2} \mathrm{O}$ (99.9\%) were purchased from Merck. Precoated silica gel plates, without fluorescent indicator, were from Merck. $\alpha$-Hydroxybutynoic acid ( $\alpha \mathrm{HB})$ was a gift from Dr. C. Walsh and was also prepared as the lithium salt as will be published elsewhere (G. Fendrich and S. Ghisla, unpublished experiments). 4,5-Dichlorouracils were a kind gift from Professor W. Pfleiderer, University of Konstanz.

Optical spectra were recorded with a Cary 118 recording spectrophotometer. Fluorescence excitation and emission spectra were recorded with a Perkin-Elmer MPF 3 spectrofluorometer or a ratio recording instrument designed and built by Dr. David Ballou and Gordon Ford, University of Michigan. Proton magnetic resonance spectra were recorded with a Varian XL-100 instrument equipped for water signal supression or with a Bruker WH 90 spectrometer, in $0.3-\mathrm{mL}$ sample tubes. Chemical shifts, in parts per million, were determined by using tetramethylsilane or sodium tetradeuterio-3-trimethylsilylpropionate as the internal standard.

Purification of Pink FMN for NMR Studies. Pink FMN, approximately $1 \mu \mathrm{mol}$, was prepared from pink FAD and purified over an apoflavodoxin column (Olson et al., 1979). The pink FMN sample was suspended in approximately $1 \mathrm{~mL}$ of $99.8 \% \mathrm{D}_{2} \mathrm{O}$, evaporated in vacuo to dryness 3 times and finally taken up in $0.3 \mathrm{~mL}$ of $99.9 \% \mathrm{D}_{2} \mathrm{O}$ for NMR measurement.

Reduction of Pink FMN with Borohydride and Separation of the Reaction Products. Approximately $1 \mu \mathrm{mol}$ of pink FMN in $0.3 \mathrm{~mL}$ of $99.9 \% \mathrm{D}_{2} \mathrm{O}$ was reduced (in an NMR tube) with $\sim 1 \mathrm{mg}$ of sodium borohydride. After a few seconds the pink color turned to lemon yellow, and, at the surface of the solution, where oxygen can react with the reduction product, formation of a red layer could be observed. After $2 \mathrm{~h}$ (NMR measurement) the solution, $\mathrm{pH} \sim 9$, was acidified with acetic acid to $\mathrm{pH} \sim 5$ and aereated thoroughly. The mixture was then separated by electrophoresis on Whatman 3 MM paper in pyridine-water (1:9), pH 6.5 (adjusted with acetic acid) at $3000 \mathrm{~V}$. After $2 \mathrm{~h}$ three bands separated; they were eluted with distilled water from the paper. The separated components were pure by chromatographic and electrophoretic criteria when visualized by their color or fluorescence but contained impurities eluted from the paper (Results, Table I). The main component, probably 6-(3-hydroxy-1-propenyl)-FMN, was applied to an apoflavodoxin column (Mayhew \& Strating, 1975 ) with a capacity of $\sim 2 \mu \mathrm{mol}$ of FMN, equilibrated with potassium phosphate, $0.05 \mathrm{M}, \mathrm{pH} 7.0$. The material was retained as a narrow yellow band on top of the column and was eluted as described in the preceding paper for purification of the pink FMN (Olson et al., 1979).

Chemical Synthesis. 8-Nitroquinolines were obtained by published procedures (Badger et al., 1963). They were reduced to the 8 -aminoquinolines in $90 \%$ yield with hydrazine and $\mathrm{Pd} /$ charcoal in ethanol.

4,5,6-Trimethyl-8-aminoquinoline was recrystallized from ethanol-water; $\mathrm{mp} 89-90^{\circ} \mathrm{C}$. Anal. Calcd for $\mathrm{C}_{12} \mathrm{H}_{14} \mathrm{~N}_{2}$ (molecular weight 186.25 ): $\mathrm{C}, 77.38 ; \mathrm{H}, 7.58 ; \mathrm{N}, 15.40 \%$. Found: $\mathrm{C}, 77.05 ; \mathrm{H}, 7.60 ; \mathrm{N}, 15.10 \%$.

8-Amino-4-methylquinoline was recrystallized from hexane; mp $84-85^{\circ} \mathrm{C}$. Anal. Calcd for $\mathrm{C}_{10} \mathrm{H}_{10} \mathrm{~N}_{2}$ (molecular weight
Table I: Chromatographic and Electrophoretic Properties of Pink Flavins

\begin{tabular}{|c|c|c|}
\hline compd & $\begin{array}{l}\text { electro- } \\
\text { phoretic } \\
\text { mobility } \\
\text { pH } 6.5^{a, b}\end{array}$ & $R_{f}$ values $^{c, d}$ \\
\hline FMN & $b$ & 0.43 \\
\hline $\mathrm{FAD}$ & & $0.26(0.6)$ \\
\hline riboflavin & $0.2^{b}$ & \\
\hline pink flavin, FAD level & & $0.15(0.35)$ \\
\hline pink flavin, FMN level & 2.2 & $0.24(0.6)$ \\
\hline pink flavin, riboflavin level & 0.87 & $0.50(1.1)$ \\
\hline 6-(3-hydroxy-1-propenyl)-FMN & 0.85 & $0.47(1.1)$ \\
\hline 6-(3-carboxy-1-propenyl)-FMN & 1.9 & - \\
\hline model compound 3 & $0.07^{b}$ & $0.60(1.4)$ \\
\hline \multicolumn{3}{|c|}{$\begin{array}{l}{ }^{a} \text { Relative to FMN. }{ }^{b} \text { In pyridine-water }(1: 9) \text { adjusted to } \mathrm{pH} \\
6.5 \text { with acetic acid, on Whatman } 3 \mathrm{MM} \text { paper. After } 1 \mathrm{~h} \text { at } \\
3000 \mathrm{~V} \text { and } 40 \mathrm{~mA} \text {, FMN migrates } 3.5 \mathrm{~cm} \text { toward the anode. } \\
\text { The model compound } 3 \text { and riboflavin migrate toward the cath } \\
\text { ode. } c \text { Values relative to FMN in parentheses. }{ }^{d} \text { In } 1 \text {-butanol- } \\
\text { acetic acid-water }(4: 3: 3) \text {, on silica gel plates. }\end{array}$} \\
\hline
\end{tabular}

158.20): C, 75.92; H, 6.37; N, 17.71\%. Found: C, 76.45; $\mathrm{H}, 6.09$; N, $17.69 \%$.

8-(Methylamino)quinoline was obtained by reduction of 8-formamidoquinoline ( $m p 145-146{ }^{\circ} \mathrm{C}$ ) with $\mathrm{LiAlH}_{4}$ in tetrahydrofuran. The oily product was condensed with 4,5dichlorouracil (Deiss, 1965) without further purification. 8-Aminoquinoline-2-carboxylic acid was synthesized according to Roth \& Erlenmeyer (1954).

General Procedure for the Preparation of 9,10-Dioxo8,9,10,11-tetrahydro-7 $\mathrm{H}$-quinolino[1,8-fg]pteridinylium Betaines. $^{2}$ A mixture of the appropriate aminoquinoline (5 $\mathrm{mmol}$ ) is thoroughly mixed with $1 \mathrm{mmol}$ of 4,5-dichlorouracil and heated in an oil bath at $190-200^{\circ} \mathrm{C}$ for $5 \mathrm{~min}$. The black residue is recrystallized from hot trifluoroacetic acid-water and yields approximately $0.3 \mathrm{mmol}$ of the product as the trifluoroacetate salt.

3,4,5,10-Tetramethyl-9,10-dioxo-8,9,10,11-tetrahydro$7 \mathrm{H}$-quinolino $[1,8-f g]$ pteridinylium trifluoroacetate (1) was obtained as orange crystals; $\mathrm{mp}>320^{\circ} \mathrm{C}$. Anal. Calcd for $\mathrm{C}_{19} \mathrm{H}_{17} \mathrm{~F}_{3} \mathrm{~N}_{4} \mathrm{O}_{4}$ (molecular weight 422.36): $\mathrm{C}, 54.03 ; \mathrm{H}, 4.06$; $\mathrm{N}, 13.27 \%$. Found: $\mathrm{C}, 53.75 ; \mathrm{H}, 4.17 ; \mathrm{N}, 13.11 \%$. Infrared (KBr): major bands at $1730,1640,1440$, and $1190 \mathrm{~cm}^{-1} ; \mathrm{m} / \mathrm{e}$ 308 (M, 100\%). 3-Methyl-9,10-dioxo-8,9,10,11-tetrahydro-7H-quinolino $[1,8-f g]$ pteridinylium trifluoroacetate (2) was obtained as yellow crystals; $\mathrm{mp}>320^{\circ} \mathrm{C}$. Anal. Calcd for $\mathrm{C}_{16} \mathrm{H}_{11} \mathrm{~F}_{3} \mathrm{~N}_{4} \mathrm{O}_{2}$ (molecular weight 380.28): C, 50.54; $\mathrm{H}$, $2.92 ; \mathrm{N}, 14.73 \%$. Found: C, 50.75; H, 2.92; N, 14.69\%. Infrared $(\mathrm{KBr})$ : major bands at $1725,1645,1570,1430$, and $1190 \mathrm{~cm}^{-1} ; m / e 266(\mathrm{M})$.

10-Methyl-9,10-dioxo-8,9,10,11-tetrahydro-7H-quinolino[1,8-fg]pteridinylium trifluoroacetate (3) was obtained as

\footnotetext{
${ }^{2}$ We thank Dr. B. Langhammer of the Beilstein Institute for proposing the name 9,11-dioxo-8,9,10,11-tetrahydro-7 $H$-quinolino[1,8-fg]pteridinylium betaine for this new class of compounds. For sake of clarity the isoalloxazine numbering (right-hand-side structure) will be used throughout the paper, the terms $\alpha, \beta$, and $\gamma$ indicating arbitrarily positions of the $\mathrm{N}(5)-\mathrm{C}(6)$ bridge as shown:

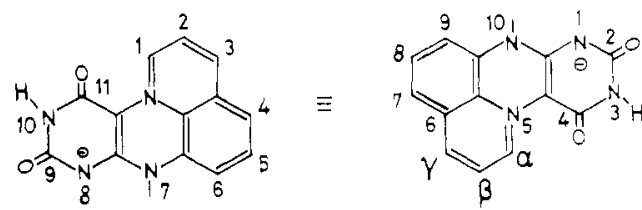

The term "pink flavin" thus refers to derivatives of this molecule carrying a ribityl residue at the isoalloxazine position $\mathrm{N}(10)$ and two methyl groups at positions 7 and 8 .
} 
Table II: Summary of NMR Data for Flavin Inhibitor Adduct ("Pink Flavin") and Model Compounds ${ }^{a}$

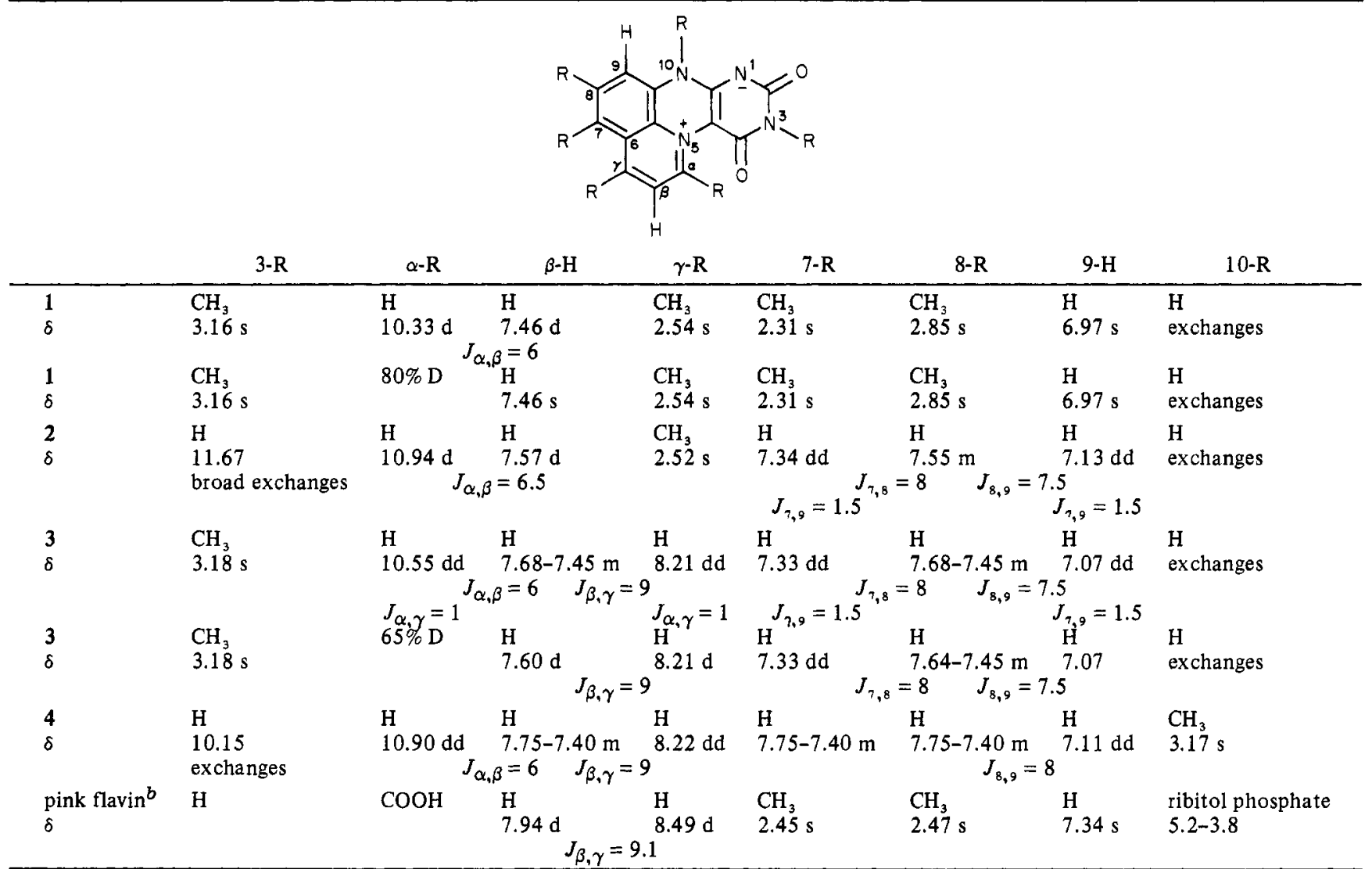

${ }^{a} J$ values are in units of hertz. Compounds $1-4$ were dissolved in dimethyl- $d_{6}$ sulfoxide, with tetramethylsilane as the reference. The pink flavin was dissolved in $99.9 \%{ }^{2} \mathrm{H}_{2} \mathrm{O}$ with sodium tetradeuterio-3-trimethylsilylpropionate as the reference. $\mathrm{s}=$ singlet; $\mathrm{d}=\mathrm{doublet} ; \mathrm{dd}=$ double doublet, signal of an $\mathrm{AB}$ doublet having a long-range $(1,3)$ coupling; $m=$ multiplet. ${ }^{b}$ Flavin inhibitor adduct.

yellow crystals; $\mathrm{mp}>320^{\circ} \mathrm{C}$. Infrared $(\mathrm{KBr})$ : closely similar to that of 1 and $2 ; m / e 266(\mathrm{M}, 100)$.

7-Methyl-9,10-dioxo-8,9,10,11-tetrahydro-7 H-quinolino$[1,8-f g]$ pteridinylium betaine (4) was obtained in only very small yields $(2-5 \%)$ and was purified by thick-layer chromatography (silica gel; 1-butanol-acetic acid-water, 4:3:1). UV and visible spectra in $0.05 \mathrm{M}$ potassium phosphate; $\mathrm{pH}$ 7.5: $\lambda_{\max } 450 \mathrm{~nm}(\epsilon 6000), 323(\epsilon 10000), 313$ and $265(\epsilon$ $33000)$. In $6 \mathrm{~N} \mathrm{HCl}: \lambda_{\max } 438 \mathrm{~nm}(\epsilon 5100), 368$ ( $\left.\epsilon 5000\right)$, $327(\epsilon 8200), 265(\epsilon 28000)$. In $1 \mathrm{~N} \mathrm{NaOH}: \lambda_{\max } 475 \mathrm{~nm}$ $(\epsilon 7400), 340(\epsilon 5200), 323(\epsilon 9400), 255$.

Exchange of ${ }^{1} \mathrm{H}$ in Position $5 \alpha$ of Compounds 1, 2, and 3 with ${ }^{2} \mathrm{H}$. A sample of the compound $(\sim 50 \mathrm{mg})$ is dissolved in a minimal amount of dimethylformamide, and upon cooling $1 / 3$ volume of water is added. To this $\mathrm{NaBD}_{4}$ is added in small portions until the color of the solution turns from red to lemon yellow, indicating completion of reduction. One drop of acetone and glacial acetic acid are added to a $\mathrm{pH}$ of $\sim 5$, and the mixture is stirred for $30 \mathrm{~min}$ at room temperature, whereby a precipitate is formed. This solid is recrystallized from trifluoroacetic acid-water; yield, 70-80\%; NMR, cf. Table II.

\section{Results}

Chromatographic Characterization of the Modified Coenzyme. The coenzyme of D-lactate dehydrogenase from $M$. elsdenii was reacted with $\alpha \mathrm{HB}$, and the modified coenzyme was released from the protein and purified as described in the preceding paper (Olson et al., 1979). It is assumed to have a structure still at the FAD level as judged from its binding behavior to the FAD-specific apo-D-amino-acid oxidase (Olson et al., 1979). The modified coenzyme is stable both when bound to the enzyme and when free in solution; this is in contrast to the $\alpha$-hydroxybutynoate-modified coenzyme of lactate oxidase (Schonbrunn et al., 1976) which was found to undergo major chemical changes after inactivation. The pink FAD analogue can be degraded stepwise, first with phosphodiesterase to an analogue of FMN, as evidenced by its binding to FMN-specific apoflavodoxin (Olson et al., 1979). With alkaline phosphatase or acid phosphatase this pink FMN is degraded to a compound which logically should be a riboflavin analogue.

The electrophoretic mobilities at $\mathrm{pH} 6.5$ of the phosphodiesterase- and phosphatase-degraded compounds indicate, by comparison to those of original FMN and riboflavin (Table I), the presence of two and one net negative charges, respectively. The mobility on thin-layer chromatography also is compatible with compounds at the levels of FAD, FMN, and riboflavin, but having a relatively more polar structure (Table I).

NMR Spectra of the Inactivated Coenzyme at the FMN Level. The Fourier transform $100-\mathrm{Hz}$ NMR spectrum (Figure 1 ) is drastically different from that of normal oxidized flavin [e.g., FMN in ${ }^{2} \mathrm{H}_{2} \mathrm{O}$ shows two singlets of the 7- and $8-\mathrm{CH}_{3}$ at approximately $2.5 \mathrm{ppm}$ and two singlets of the 6- and 9-H at approximately $7.8 \mathrm{ppm}$ (Scola-Nagelschneider \& Hemmerich, 1976)]. The signals at 8.49, 7.94, 7.34, and $2.45 \mathrm{ppm}$ integrate to a ratio of $1: 1: 1: 6$ protons. Thus, the signal at 2.45 can be attributed to the nearly converging peaks of the two methyl groups originally at positions 7 and 8 of the isoalloxazine nucleus. This effect of coincidence is in contrast to what is found with oxidized flavins (Scola-Nagelschneider \& 


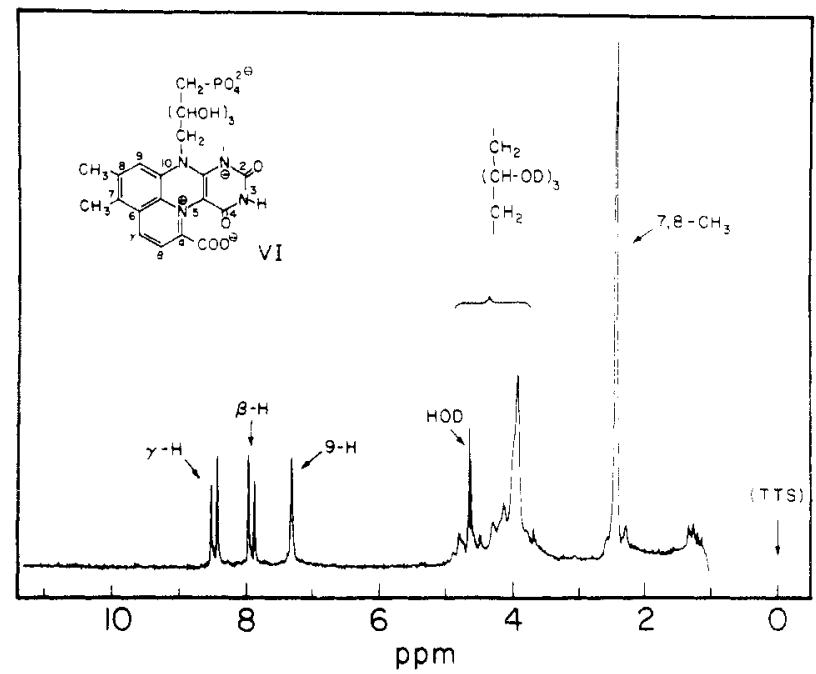

FIGURE 1: Fourier transform NMR spectrum of the flavin adduct isolated from $\alpha$-hydroxybutynoate-inactivated D-lactate dehydrogenase, after its hydrolysis with Naja naja phosphodiesterase and purification over an apoflavodoxin affinity column (pink FMN).

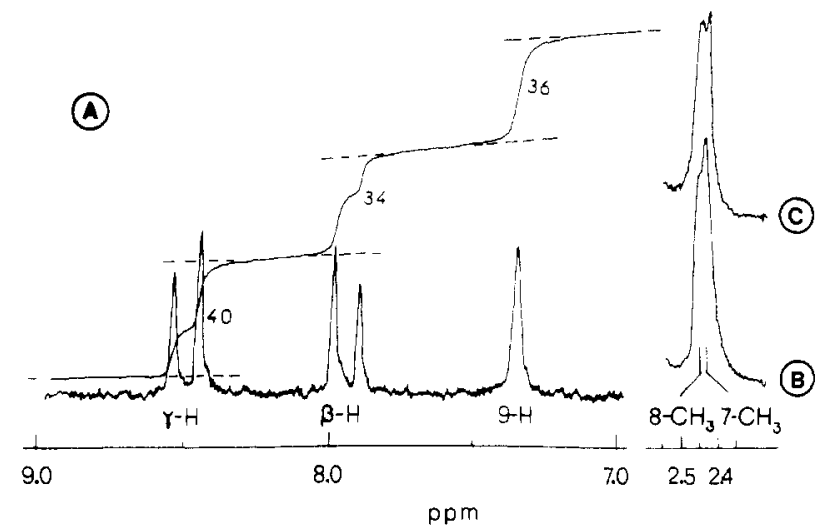

FIGURE 2: Fourier transform NMR spectrum of the aromatic protons of the pink FMN in ${ }^{2} \mathrm{H}_{2} \mathrm{O}$ observed under saturating irradiation at the frequency of the $7,8-\mathrm{CH}_{3}$ groups (A). The corresponding integration, calibrated in arbitrary units, exhibits a nuclear Overhauser enhancement for the $\gamma-\mathrm{H}$ and $9-\mathrm{H}$ protons (18 and $6 \%$, respectively). The integrated intensities of these two protons are equal to that of the $\beta-\mathrm{H}$ when the spectrum is recorded under the same conditions but with the decoupling power set at $1000 \mathrm{~Hz}$ upfield from $\mathrm{Me}_{4} \mathrm{Si}$. (B) shows the expanded spectrum of the 7,8- $\mathrm{CH}_{3}$ groups, and (C) shows the same portion recorded while $9-\mathrm{H}$ was being decoupled.

Hemmerich, 1976) but similar to the case of reduced flavins (Ghisla et al., 1973). That the 2.45-ppm peak indeed consists of two signals is demonstrated in Figure 2, where expansion of the spectrum first reveals the presence of a low-field shoulder. Upon decoupling by irradiation at $7.34 \mathrm{ppm}(9-\mathrm{H})$, the signal resolves into two peaks separated by $0.02 \mathrm{ppm}$, which therefore can be attributed to the intact $8-\mathrm{CH}_{3}$ and $7-\mathrm{CH}_{3}$ groups in order of increasing field (Table II).

The spectrum of the pink flavin (Figure 1) shows only one aromatic proton singlet at $7.34 \mathrm{ppm}$. This indicates that, as compared with oxidized flavin, one aromatic proton has been lost in the process of inactivation and has been substituted by a residue which must originate from covalent addition of $\alpha \mathrm{HB}$ to the flavin. The assignment of this signal to a proton in position 6 or 9 of the original isoalloxazine moiety is substantiated by comparison with the chemical shifts of the models 1-4 (Table II) and by the results from the NOE (nuclear Overhauser effect) and decoupling experiments depicted in Figure 2: irradiation at the frequency of the $7,8-\mathrm{CH}_{3}$ signal causes a $7-10 \%$ enhancement of the intensity of the aromatic 9-H signal, while irradiation at $7.34 \mathrm{ppm}(9-\mathrm{H})$ leads to
Scheme I

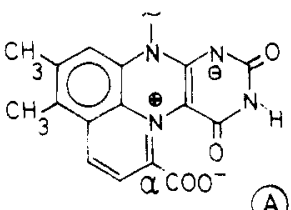

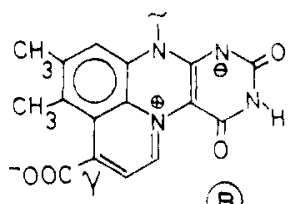

(B)<smiles></smiles>

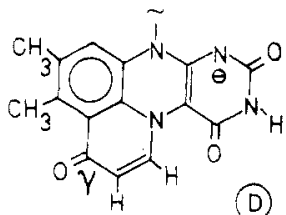

resolution of the $7,8-\mathrm{CH}_{3}$ signal as discussed above.

The two remaining doublets at $7.9-8.5 \mathrm{ppm}$ belong to two aromatic protons of an $\mathrm{AB}$ system, as can be demonstrated by reciprocal decoupling (not shown). One of these protons should originate from the $\gamma$ proton of $\alpha \mathrm{HB}$, while the second should be incorporated from solvent during the process of inactivation, by a mechanism similar to that postulated in the case of lactate oxidase (Schonbrunn et al., 1976).

The inactivation of $\mathrm{D}$-lactate dehydrogenase thus involves covalent addition of the inactivator and leads to formation of a new aromatic ring. The points of connection of the latter with the flavin moiety therefore involve the positions $\mathrm{N}(5)$ and $\mathrm{C}(6)$. The possibility of an alternative ring attachment involving position 9 , although not rigorously excluded by the NMR data, is eliminated because it would involve loss of the $\mathrm{N}(10)$ ribityl side chain, which, however, is intact (Figure 1). This assumption implies that the $\alpha-\mathrm{H}$ and either the $\alpha-\mathrm{OH}$ or carboxylate function of $\alpha \mathrm{HB}$ have been removed during the process of coenzyme modification.

The NMR data, however, do not yield any information on the fate of the coenzyme pyrimidine ring, which might have hydrolyzed as in the case of L-lactate oxidase (Schonbrunn et al., 1976). It will be shown later that the pyrimidine ring is still intact in pink flavin. Therefore, structures, A-D (Scheme I), which all show a potential aromatic AB system and have a net negative charge, should be discussed.

Structures $C$ and $D$ would have undergone an oxidative decarboxylation, a process which cannot be excluded, but which is very improbable, as inactivation to yield the pink flavin proceeds under anaerobic conditions. Structure $C$ is unlikely because it would constitute an alkylated reduced flavin, a species with $\lambda_{\max }$ around $310 \mathrm{~nm}$ (Dudley et al., 1964). Furthermore, in compounds such as $\mathrm{C}$ and $\mathrm{D}$, the $\mathrm{N}(1)-\mathrm{H} \mathrm{pK}$ should be in the region 6-7, the same as with reduced flavins (Ghisla et al., 1974), while a $\mathrm{p} K$ of approximately 3.1 is found for pink flavin (cf. below).

The NOE experiment shown in Figure 2 was designed in order to differentiate between structures $\mathrm{A}$ and $\mathrm{B}$ (or D). Here, irradiation is carried out at the frequency of the $7,8-\mathrm{CH}_{3}$ groups; this causes a $15-25 \%$ (depending on the sample and the presence of $\mathrm{O}_{2}$ ) relative enhancement of the downfield signal $(8.49 \mathrm{ppm})$ while the signal at $7.97 \mathrm{ppm}$ is unaffected. This unambiguously attributes the two aromatic doublets to protons in positions $5 \beta$ and $5 \gamma$ in order of decreasing field (Figures 1 and 2) and confirms structure A. Furthermore, in the model compounds $1-4$, the $5 \alpha-\mathrm{H}$ has a chemical shift of 10.3-10.9 ppm, while the chemical shifts of the model's $\beta$ and $\gamma$ protons correspond with those of the pink flavin (Table II). Further support for structure A comes from the chemical 


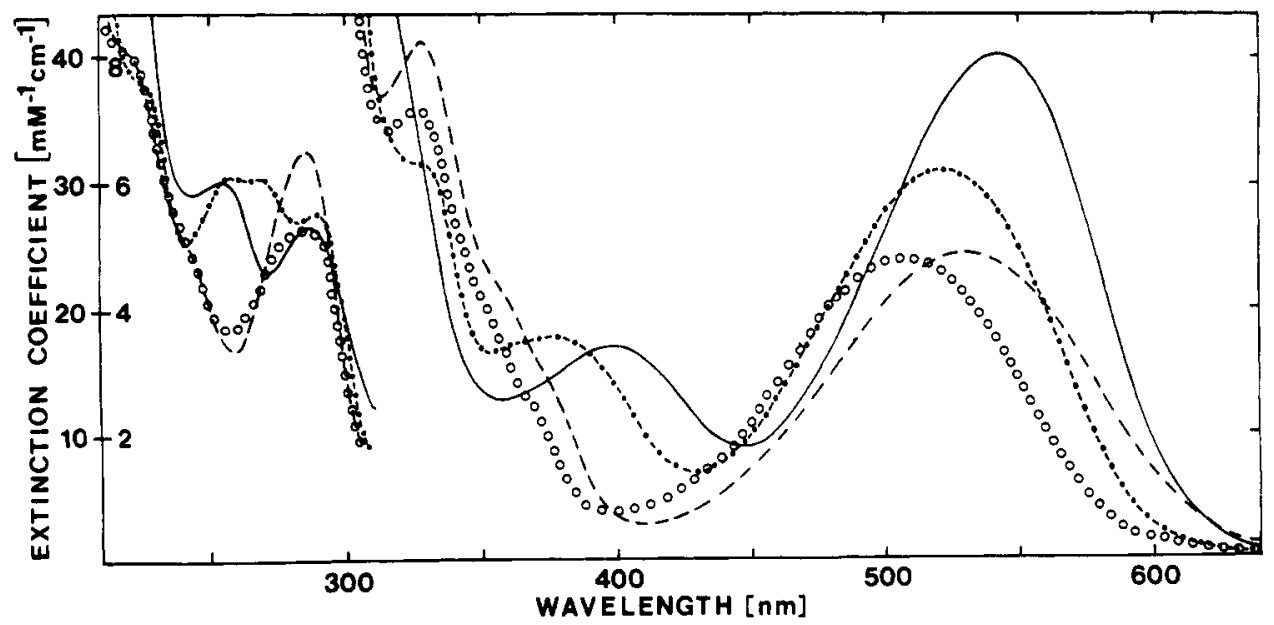

FIGURE 3: Absorption spectrum of pink riboflavin as a function of $\mathrm{pH}$. Spectra of the pink riboflavin were recorded at $2.3 \times 10^{-5} \mathrm{M}$ in $20 \%$ (w/w) $\mathrm{H}_{2} \mathrm{SO}_{4}, H_{0}=-1(\cdots)$, dilute $\mathrm{HCl}, \mathrm{pH} 2.18(\mathrm{O} \circ \mathrm{O}), \sim 10 \mathrm{mM} \mathrm{KP}$, $\mathrm{pH} 6.60(\cdots)$, and $1 \mathrm{~N} \mathrm{KOH}(-)$.

reactivity of the pink flavin detailed below.

The signals of the pink flavin pentityl side chain (Figure 1) are very similar to those of normal FMN, i.e., appear at 3.8-5.2 ppm (Scola-Nagelschneider \& Hemmerich, 1976), and thus indicate an intact ribityl phosphate structure. This conclusion can also be deduced from the demonstrated tight binding of the pink flavin to apoflavoproteins (Olson et al., 1979).

Light Absorption Properties of the Modified Coenzyme. The absorption of the pink flavin chromophore at the FMN and riboflavin level between pH 5 and 10 (Figure 3) is characterized by a single band in the visible maximum at 522 $\mathrm{nm}$. The spectrum shows a marked dependence on $\mathrm{pH}$. These changes are reversible with clearly defined isosbestic points reflecting $\mathrm{p} K$ values at $1.1,3.1$, and 12.3 . Changes in the fluorescence emission spectra accompany these absorption changes, emission maxima occurring at $\lambda_{\max } 640,650$, and 640 $\mathrm{nm}$ at $\mathrm{pH} 6.60$, in $1 \mathrm{~N} \mathrm{KOH}$, and $\mathrm{pH} 2.18$, respectively. The emission intensities are 1.9 and 0.6 times the intensity of the neutral species in $1 \mathrm{~N} \mathrm{KOH}$ or $\mathrm{pH} 2.18$, respectively, with the fully protonated species being devoid of fluorescence when measured at $25^{\circ} \mathrm{C}$.

Comparison of the spectra of the pink flavin chromophore (Figure 3) with those of the model compound (Figures 6 and 7 below) reveals that similarities are restricted to the spectrum of model 1 in its anionic state or in apolar medium. As the absorption of the model compounds depends only to a minor extent on the nature of the substituent in position $\mathrm{N}(10)$ (cf. compounds 1, Figure 6, and 4; also see Materials and Methods), or on that of the substituents at positions N(3) (compare 1 and 2), $5 \gamma$, or 8 (compare 2 and 3 ), it is assumed that the spectral difference will originate from the effect of the carboxyl function at position $5 \alpha$. The effect of this group might reside in a preferential stabilization of one specific mesomeric form of the several possible for the pink flavin betaine structure, an effect possibly similar to that induced by nonpolar solvents on the chromophore of the models 1-3.

By comparison with the first $\mathrm{p} K$ of model 1 (3.65), the $\mathrm{p} K$ at 3.1 is attributed to protonation of the pink flavin at position $N(1)$ (or at the tautomeric positions $C(2)=0$ or $C(4)=0$ ). The $\mathrm{p} K$ at 1.1 could correspond to protonation of the carboxylate function at position $5 \alpha$. The $\mathrm{p} K$ at 12.3 most probably reflects deprotonation at the pyrimidine $\mathrm{N}(3)-\mathrm{H}$, as qualitatively the same spectral shifts are obtained upon deprotonation of the $\mathrm{N}(10)$-blocked model $4(\mathrm{p} K \sim 12)$.

Chemical Reactivity of the Pink Flavin. The pink flavin chromophore at its FAD or FMN level does not react with

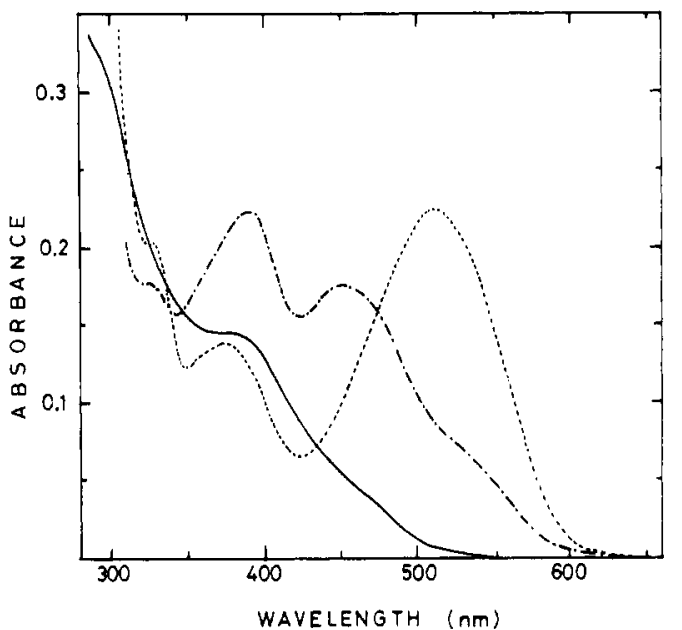

FIGURE 4: Spectral course of $\mathrm{NaBH}_{4}$ reduction of pink FMN and of its reoxidation by air. Pink FMN, $3.8 \times 10^{-5} \mathrm{M}$ in $0.05 \mathrm{M}$ phosphate buffer, $\mathrm{pH} 7.0$, was made anaerobic $(---)$, and then approximately $1 \mathrm{mg}$ of solid $\mathrm{NaBH}_{4}$ was added from a side arm. After approximately $10 \mathrm{~min}$ the decrease of the $521-\mathrm{nm}$ absorption band had ceased, and a spectrum $(-)$ was obtained. The $\mathrm{pH}$ of the solution was $\sim 9$. The solution was then acidified to $\mathrm{pH} \sim 4$ with acetic acid in order to destroy excess $\mathrm{BH}_{4}^{-}$and shaken thoroughly with air. An intermediate spectrum with absorption at $\sim 600 \mathrm{~nm}$ and a maximum around $510 \mathrm{~nm}$ was first observed. This species decays and yields after approximately $10 \mathrm{~min}$ the spectrum represented by $(-\cdots)$.

dithionite, indicating that it is, formally, at the level of reduced flavin. Its spectrum is, however, rapidly bleached by high concentrations of sulfite $(\sim 1 \mathrm{M})$. The pink FMN is also reduced rapidly by $\mathrm{NaBH}_{4}$. Under anaerobic conditions, this process leads to disappearance of the 522-nm band (Figure 4) and to formation of a spectrum similar to that of 1,5dihydroflavins (Ghisla et al., 1974). This species is very sensitive to oxygen; reoxidation leads to an increase of $a b-$ sorption at $\lambda>350 \mathrm{~nm}$ but not to re-formation of the original spectrum (Figure 4). Fluorescence excitation and emission spectra of the product indicate at least two species, while thin-layer chromatography and electrophoresis at $\mathrm{pH} 6.5$ show a pink spot, identical with starting material (pink FMN), and two yellow fluorescing components (Table I). The main yellow component has an electrophoretic mobility very similar to that of FMN (Table I), indicating that, as compared to pink FMN, it has lost one net negative charge. It constitutes $60-70 \%$ of the total material recovery, as judged from the fluorescence and color intensity on thin-layer chromatography, as well as from the recovery from preparative electrophoresis. The 


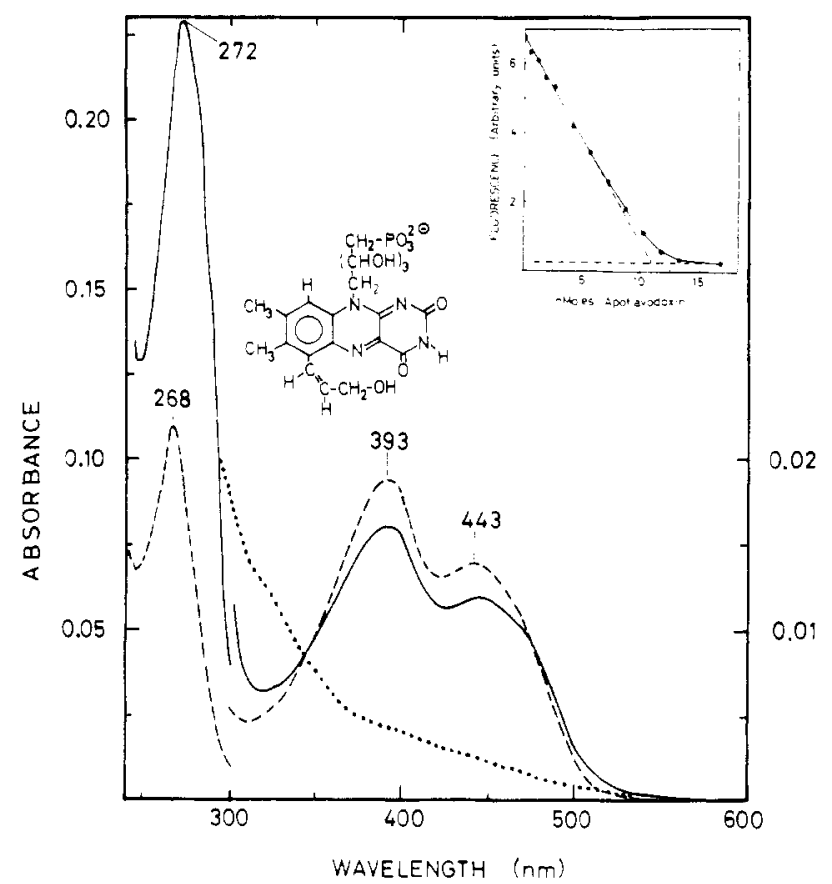

FIGURE 5: Absorption spectrum of 6-(3-hydroxy-1-propenyl)-FMN free in solution, bound to apoflavodoxin, and in its reduced form. (..-) represents the spectrum of the FMN analogue, $1.5 \times 10^{-6} \mathrm{M}$ in 0.05 $\mathrm{M}$ phosphate buffer, $\mathrm{pH} 7.0$, at $25^{\circ} \mathrm{C}$. This species was titrated with increments of apoflavodoxin, and the fluorescence emission ( $\lambda_{\text {excitation }}$ $=460 \mathrm{~nm}$ ) was detected at $520 \mathrm{~nm}$ (inset). The spectrum of the complex in the presence of 1.5 equiv of apoflavodoxin is shown by $(-) .(\cdots)$ represents the spectrum of the free modified FMN after anaerobic illumination in the presence of $10^{-2} \mathrm{M}$ EDTA at $4{ }^{\circ} \mathrm{C}$ for $1 \mathrm{~min}$, with a 250 -W tungsten/halogen lamp at $10-\mathrm{cm}$ distance from the light source. The course of the photoreduction is isosbestic. Admission of air immediately restores $96 \%$ of the starting spectrum.

electrophoretic mobility of the second minor yellow component indicates that it has two net negative charges (Table I). When the $\mathrm{BH}_{4}^{-}$reduction was carried out in the NMR tube used for the above-described experiments, a similar bleaching occurred; an NMR spectrum could not be obtained, probably due to the presence of radical impurities.

The absorption spectra of the two yellow components are very similar to each other, the main component being shown in Figure 5. Both compounds also have the same fluorescence emission, $\lambda_{\max }=530 \mathrm{~nm}$, the main component having an emission intensity $25 \%$ that of FMN. These spectral data, including the extinction coefficients $\left(\epsilon_{443} \sim 9500 ; \epsilon_{393} \sim\right.$ 12500), are very similar to those of isoflavins (Mayhew, 1971), i.e., to oxidized flavin chromophores carrying a substituent at position 6.

In order to test the hypothesis that the $\mathrm{BH}_{4}{ }^{-}$reduction- $\mathrm{O}_{2}$ reoxidation process has lead to a modified oxidized FMN analogue, the major yellow compound with electrophoretic mobility similar to that of FMN was further purified on a flavodoxin column (cf. Materials and Methods), and the eluted material was titrated with apoflavodoxin. The inset of Figure 5 shows that this FMN derivative is bound with a $K_{d} \sim 5 \times$ $10^{-8} \mathrm{M}$, its fluorescence is quenched in the complex to $2-3 \%$ that of the free compound, and the spectral perturbations observed upon binding are closely similar to those observed by Mayhew (1971) upon binding of iso-FMN to the same apoflavodoxin. It should be noted that this FMN analogue binds better than pink FMN to apoflavodoxin $\left[4.5 \times 10^{-7} \mathrm{M}\right.$; Olson et al. (1979)] and compares to the binding of normal FMN [ $4 \times 10^{-10}$ M; Mayhew (1971)]. The yellow chromophore is reversibly reduced by dithionite or EDTA/light to a species having a featureless spectrum (Figure 5) remi-
Scheme II

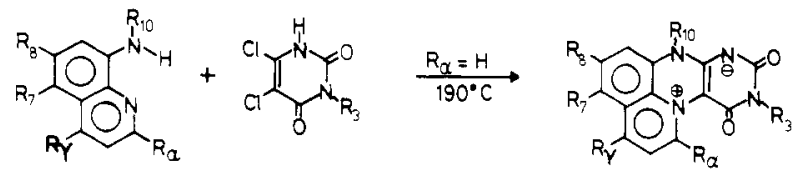

niscent of those of 1,5-dihydroflavins (Ghisla et al., 1974), These findings clearly prove the presence of a flavinlike redox system in which the pyrimidine ring is still intact.

The sum of this evidence indicates that the aromatic ring assumed to bridge $N(5)$ and $C(6)$ in the pink flavin has been cleaved and that in the main product the carboxylate function has been lost. Therefore, we propose $6-\left(3-\mathrm{OH}^{-}\right.$or $3-$ $\mathrm{COO}^{-}$-1-propenyl)-FMN structures (cf. structure inset, Figure 5) for the two yellow components in question.

Synthesis and Properties of Model Compounds. The modified isoalloxazine required for the structural elucidation of the inactivated coenzyme is obtained in a straightforward manner by condensation of appropriately substituted 8 aminoquinolines with 4,5-dichlorouracils (Scheme II). This synthetic approach unfortunately fails, probably for steric reasons (overcrowding of the $\mathrm{C}(4)=\mathrm{O}$ and $\mathrm{R}_{\alpha}$ functions as shown by space-filling models), when $\mathrm{R}_{\alpha}=\mathrm{COOH}$ or $\mathrm{CH}_{3}$. On the other hand, the product yield is improved by the presence of positively inductive $(+I)$ substituents $\left(R_{\gamma}\right.$ and $\left.R_{8}\right)$ in the aminoquinoline moiety. The structure of compounds 1-3 (Table II) is confirmed by elemental analysis and mass spectroscopy (cf. Materials and Methods) and by NMR (Table II). The unequivocal attribution of the NMR signals is of importance in view of the previously discussed structural elucidation of the inactivated $\mathrm{D}$-lactate dehydrogenase coenzyme. The signals of the $\mathbf{R}_{3}, \mathbf{R}_{\gamma}, \mathbf{R}_{7}$, and $\mathbf{R}_{8}$ protons (or methyl groups) were attributed by comparison of the compounds carrying either methyl groups or protons at these positions (Table II). $\mathrm{H}_{9}$ is clearly identified as a singlet in compound 1 ; its selective decoupling in compound 2 allows direct attribution of $\mathrm{H}_{8} . \mathrm{H}_{\gamma}$ is identified by comparison of 1 and $\mathbf{2}$ (where $\left.\mathrm{R}_{\gamma}=-\mathrm{CH}_{3}\right)$ with $\mathbf{3}\left(\mathrm{R}_{\gamma}=\mathrm{H}\right) . \mathrm{H}_{\alpha}$ is logically the signal appearing at lowest field, as expected for an immonium-type proton. This attribution is confirmed by deuterium-exchange experiments. In fact, in compound 1 , incorporation of ${ }^{2} \mathrm{H}$ by reduction with $\mathrm{BD}_{4}^{-}$, followed by oxygen reoxidation, is expected to occur at the iminelike position $5 \alpha$. In the $5 \alpha$-deuterated compound $1, \mathrm{H}_{\beta}$ now appears as a singlet, thus allowing its unambiguous identification.

The electronic spectra of the model compounds 1-3 are remarkable in that they show a strong solvatochromy (Figure 6) and dependence on the state of ionization (Figure 7). Between the two extreme types of spectra as shown in Figure 6 , a series of intermediate spectra can be generated by using either solvent mixtures or solvents of intermediate properties. The similarity of the spectra of compound 1 in its neutral and cationic forms (Figure 7) with those of the corresponding forms of the analogous N(10)-blocked model compound (Materials and Methods) indicate that in the neutral forms of compounds 1-3 the exchangeable $\mathrm{N}-\mathrm{H}$ proton is located at $\mathrm{N}(10)$ and not at $\mathrm{N}(1)$. Furthermore, only compounds $1-3$, but not the $\mathrm{N}(10)$-blocked 4, show a strong bathochromic shift of the lowest energy transition in the monoanionic state, thus indicating that deprotonation occurs at $\mathrm{N}(10)$. Therefore the $\mathrm{p} K$ values of 3.65 and 12.1 found with compound 3 (Figure 7) are attributed to $N(1)$ and $N(10)$, respectively. The spectrum of 3 in aprotic, nonpolar solvents (Figure 6) strongly resembles that of the anionic compound 3 (Figure 7), and both are similar to that of the inactivated coenzyme, indicating the 


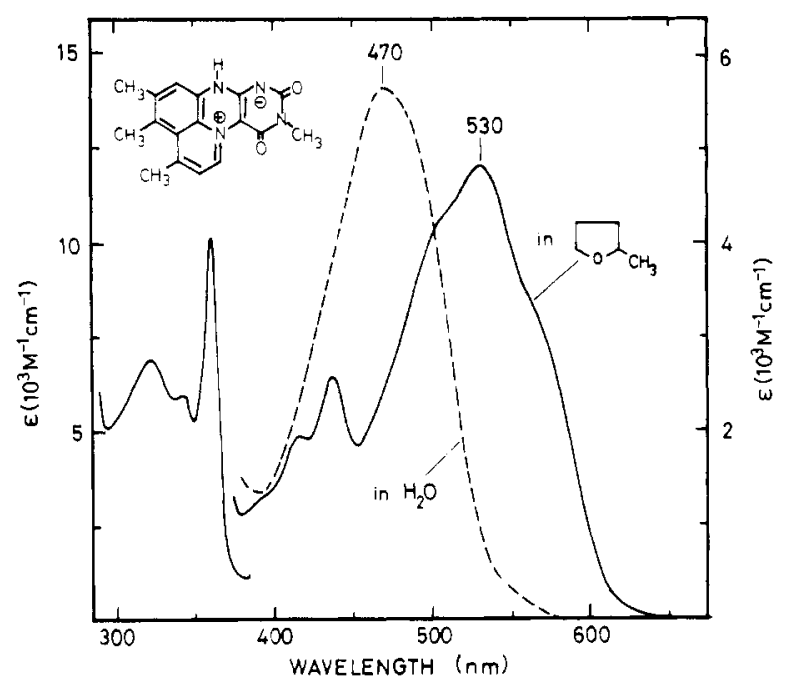

FIGURE 6: Absorption spectrum of the model compound $1(3,4,-$ 5,10-tetramethyl-9,11-dioxo-8,9,10,11-tetrahydro-7 $H$-quinolino$[1,8-f g]$ pteridinylium betaine) as function of solvent polarity. (-.) In $0.1 \mathrm{M} \mathrm{NaCl}$ solution; (-) in 2-methyltetrahydrofuran.

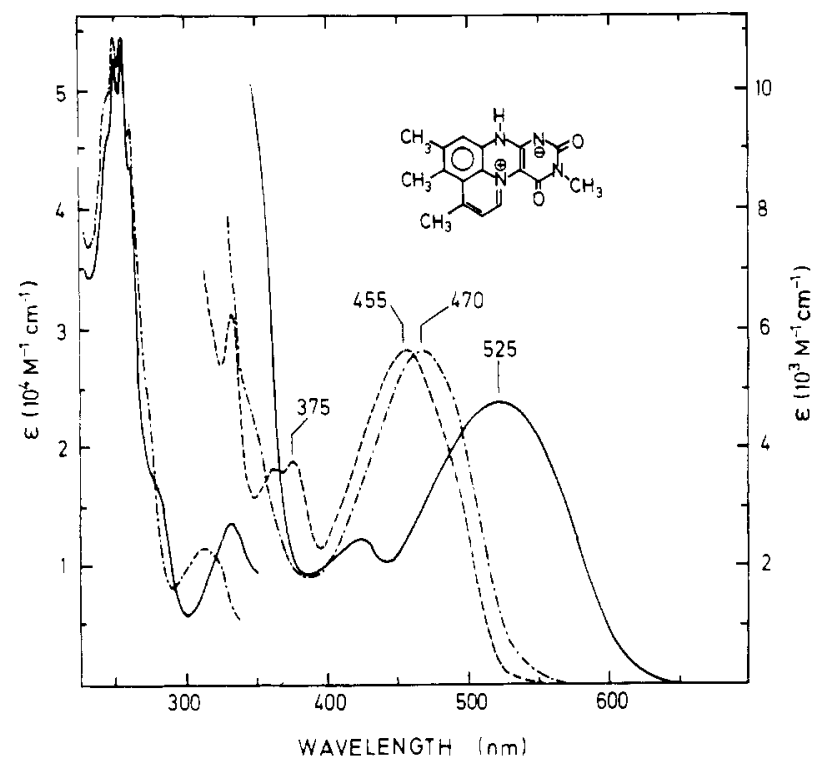

FIGURE 7: Absorption spectrum of the model compound $1(3,4,-$ 5,10-tetramethyl-9,11-dioxo-8,9,10,11-tetrahydro- $7 \mathrm{H}$-quinolino$[1,8-f g]$ pteridinylium betaine) as a function of $\mathrm{pH}$. The solutions were $2.3 \times 10^{-5} \mathrm{M}$ in $0.1 \mathrm{M} \mathrm{NaOH}(-)$, in $0.05 \mathrm{M}$ phosphate buffer, $\mathrm{pH}$ $7.0(\cdots)$, and in $6 \mathrm{~N} \mathrm{HCl}(-\cdots)$.

presence of comparable chromophores. This phenomenon as well as the spectral shifts observed upon formation of the anions of compounds 1-3 might originate in the different stability of tautomeric (and mesomeric) forms as a function of ionization state and solvent properties and is not uncommon to chromophores having betaine structures as pictured in Scheme III.

The absorption spectra of compounds 1-3 are only slightly dependent on the nature of substitution at the positions 7,8 , and $10\left(\mathrm{H}_{\text {or }} \mathrm{CH}_{3}\right)$, the differences in $\lambda_{\max }$ being maximally of the order of $\pm 20 \mathrm{~nm}$ at $\lambda>400 \mathrm{~nm}$. The chromophore in its neutral and cationic state and at $25^{\circ} \mathrm{C}$ has a fluorescence which is maximal at $520-540 \mathrm{~nm}$ in aqueous solvents. Compound 3 in its anionic form and in apolar solvent has a very weak emission, maximal around $550 \mathrm{~nm}$, its excitation spectrum being similar to the absorption spectrum of the neutral form in aqueous solvent and thus probably originating from contributions of the corresponding tautomeric/mesomeric form still present in minor amounts.
Scheme III

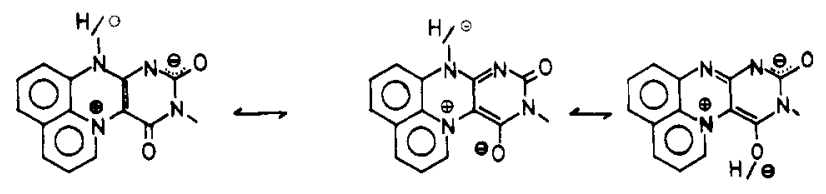

Similar to pink FMN, the N(10)-blocked analogue of pink flavin 4, but not the unsubstituted models 1-3, was found to be bleached by high concentrations of sulfite. The model compounds 1-4 do not react with dithionite but are rapidly reduced by sodium borohydride in DMF-water $(1: 1)$ to yield, in the case of 1 , a yellow fluorescing species with absorption $\lambda_{\max }=405 \mathrm{~nm}$. The reactivity of this species toward oxygen is very high and similar to that of reduced flavins and alloxazines (Ghisla et al., 1973); thus, this intermediate most probably represents a 1,5-dihydroalloxazine species as shown in Scheme V (cf. Discussion). When the oxygen reoxidation is carried out at pH 5.5, the spectral course of the reaction is isosbestic and leads directly to $90 \%$ re-formation of compound 1 . That borohydride reduction is occurring at position $5 \alpha$ is supported by the finding that deuterium is incorporated in position $5 \alpha$ of 1 and 3 but not in the vinylogue position of compound 3 (Table II).

Compound 1 is reduced catalytically $\left(\mathrm{H}_{2} / \mathrm{Pd}\right)$ to a dihydrolumichrome analogue bridged at positions 5 to 6 by a now fully hydrogenated ring. The reoxidation of this species proceeds over the 5-substituted alloxazine cation (Ghisla et al., 1972), which decays to a 6-substituted lumichrome. The chemistry of this new class of compounds will be detailed elsewhere (S. Ghisla and M. Janda, unpublished experiments).

\section{Discussion}

The evidence presented above indicates that the pink chromophore obtained after inactivation of D-lactate dehydrogenase with $\alpha \mathrm{HB}$ arises from covalent cyclic addition of the inhibitor to positions $N(5)$ and $C(6)$ of the coenzyme isoalloxazine moiety. The structure of this adduct, at the FMN level, is shown in Figure 1. In the case of L-lactate oxidase, the same suicide inhibitor forms a different cyclic flavin adduct, giving a five-membered ring involving positions $\mathrm{C}(4 \mathrm{a})$ and N(5) (Schonbrunn et al., 1976). With lactate oxidase, kinetic data are consistent with a mechanism in which reduction of the flavocoenzyme (a process identical with oxidation of the inhibitor) is faster than inactivation (Ghisla et al., 1976). With the same enzyme, however, chemical considerations, as well as the absence of inactivation with vinylglycollate, suggest that inactivation is initiated by addition of an allene carbanion to the flavin $C(4 a)$ position (Schonbrunn et al., 1976). Unfortunately, a clear mechanistic alternative did not emerge (Schonbrunn et al., 1976).

In the present case of D-lactate dehydrogenase, the possible pathways leading to inactivation are summarized in Scheme IV. The three steps 1,2 , and 3 represent processes which should occur during substrate turnover. Step 1, the formation of the $\alpha$-carbanion I, is now regarded as the event initiating oxidation, at least with substrates in which the $\mathrm{C}-\mathrm{H}$ function is flanked by an activating group. The subsequent catalytic steps involve transfer of 2 redox equiv and may proceed by group transfer (steps 2 and 3 ) and involve covalent adducts such as II. Such covalent adducts have indeed been shown to occur with the enzymes D-amino-acid oxidase (Porter et al., 1973) and L-lactate oxidase (Massey \& Ghisla, 1975); Ghisla \& Massey, 1978). A reduced enzyme- $\alpha$-ketobutynoic acid complex such as III has been shown to occur during the formation of the covalent adduct with lactate oxidase (Ghisla 
Scheme IV: Possible Modes of Covalent Adduct Formation between the Coenzyme of $\mathbf{D}$-Lactate Dehydrogenase and $\alpha \mathrm{HB}^{a}$

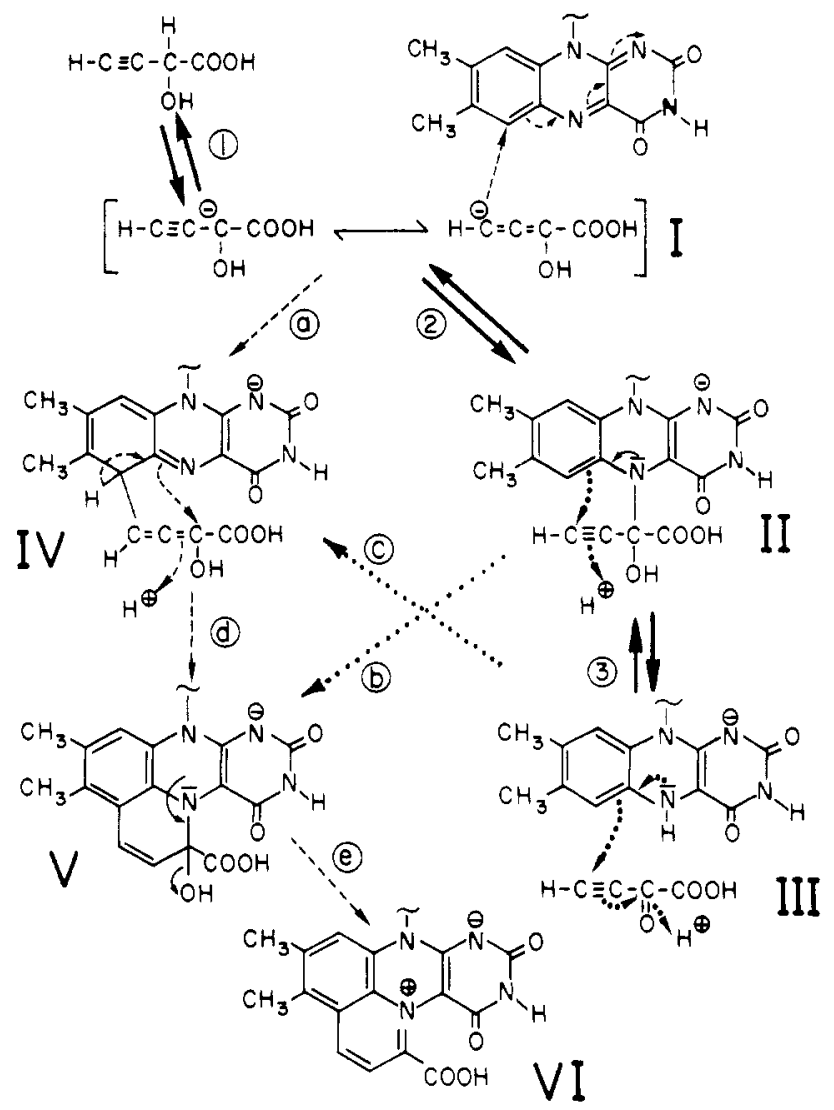

${ }^{a}$ The scheme represents reactions occurring at the enzyme active center.

et al., 1976) and might occur also with D-lactate dehydrogenase (Olson et al., 1979). However, the species I-III could exist in a rapid equilibrium, the same as in the case of the lactate oxidase-glycollate reaction (Ghisla \& Massey, 1978).

In the present case the crucial event in the process of adduct formation will be the formation of the new bond between the inhibitor $\gamma$-carbon and the flavin position $C(6)$, i.e., either one of steps $a, b$, or c of Scheme IV. Step c represents a Michael-type addition. The flavin of D-lactate dehydrogenase is not modified by vinylglycollate (Olson et. al., 1979), which is oxidized by the enzyme to the Michael-active $\alpha$-ketobutenoate; the latter is at least as good a Michael reagent as $\alpha$-ketobutynoate (Schonbrunn et al., 1976). This inertness is shared with a series of similar flavoproteins, which are all inactivated by $\alpha \mathrm{HB}$ (Schonbrunn et al., 1976; Walsh et al., 1972; Cromartie \& Walsh, 1975; Jewess et al., 1975). Furthermore, the $\mathrm{C}(6)$ position of reduced flavin has never been observed to undergo any reactions and, therefore, should be a much less effective nucleophile as compared to positions $N(5)$ and $C(4 a)$. Since formation of the $C(6)$-inhibitor bond appears to occur at a rate comparable to reduction in D-lactate dehydrogenase (Olson et al., 1979), while formation of the covalent linkage between the inhibitor and the flavin $C(4 a)$ or $N(5)$ positions appears much slower as compared to reduction in lactate oxidase (Ghisla et al., 1976), a Michael mechanism would be inconsistent with the expected order of nucleophilicity of positions $\mathrm{C}(4 \mathrm{a}), \mathrm{N}(5)$, and $\mathrm{C}(6)$. Therefore, a step such as step $c$ appears very improbable as the event initiating inactivation. Similarly, a cyclization of the adduct II (Scheme IV, step b) appears very unlikely. In fact, with $\mathrm{N}(5)-\mathrm{CH}_{2} \mathrm{C}=\mathrm{CH}$ reduced model flavins, a cyclization to $\mathrm{C}(6)$ does not occur, while ring closure to $C(4 a)$ appears com-
Scheme V: Possible Mechanism for Trapping an Oxygen-Sensitive Intermediate on the Path to Pink Flavin

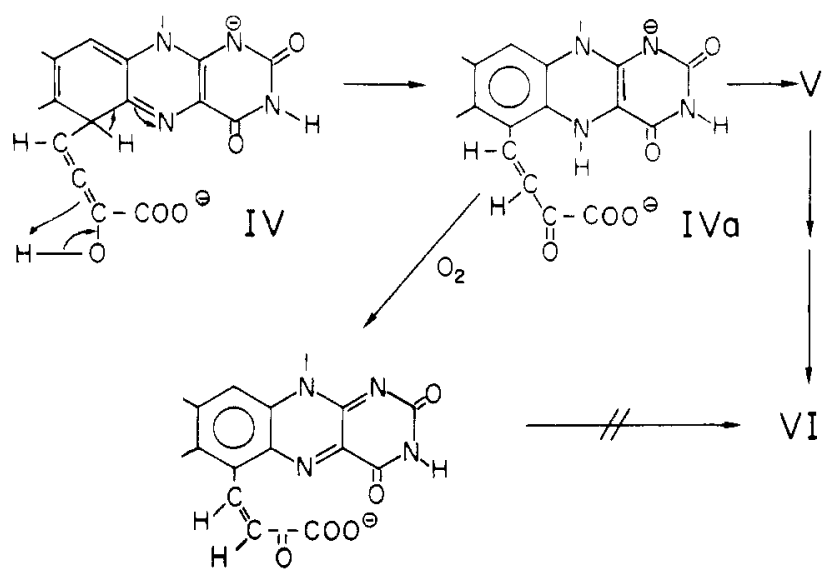

paratively facile (Gaertner et al., 1976). For the inactivation being initiated by step a, the following arguments can be mustered. Examples of electrophilic activity of the oxidized flavin position 6 are known (Hevesi \& Bruice, 1973). The same position is photoreactive (Schoellnhammer \& Hemmerich, 1974) and is probably being hydroxylated in bacterial electron-transferring flavoprotein (Mayhew et al., 1974). With alloxazine models, a substituent migration to position $\mathrm{C}(6)$ has been observed (Ghisla et al., 1972). Furthermore, the allene anion I (Scheme IV) represents a highly reactive nucleophilic species which should be expected to react in the way shown (Scheme IV).

The pink flavin structure allows deductions regarding the structure of the intermediate which is trapped by oxygen at $\mathrm{pH} 8.5$ (Olson et al., 1979). Its facile conversion to pink flavin implies that a covalent attachment of the substrate to the flavin must have already occurred. This attachment is presumed to be through $\mathrm{C}(6)$ from the similarity of its spectrum to that of the products obtained upon $\mathrm{BH}_{4}^{-}$reduction and reoxidation of the pink flavin (Figure 5). This species could arise as an intermediate in reaction d being formed from IV by a prototropic $\mathrm{C}(6)$ to $\mathrm{N}(5)$ shift to form IVa (Scheme V), which subsequently undergoes ring closure to form V (cf. Scheme IV). In contrast to the intermediate IVa, which has a 1,5dihydroflavin structure, the cyclic adduct $V$ should not react with oxygen, as $\mathrm{N}(5)$-substitution of enzyme-bound or free flavins reduces their oxygen sensitivity drastically (Ghisla et al., 1973; Walker et al., 1970; Massey \& Ghisla, 1975).

The sum of evidence presented strongly argues, in our opinion, in favor of a carbanion-type minimal mechanism as depicted on Scheme IV by the sequence 1, 2, and 3 for catalysis and by steps $1, a, d$, and e for inactivation. A further differentiation of processes such as steps a and 2 into single $1 \mathrm{e}^{-}$ transfer steps [radical mechanism, cf. Bruice 1976)] clearly also would be in accordance with the above-proposed mechanism.

The course of $\mathrm{BH}_{4}^{-}$reduction of pink flavin and of its reconversion to an oxidized isoalloxazine gives additional evidence to the $5 \alpha$ location of the carboxylate function in pink flavin. With pink FMN borohydride reduction is envisaged to occur at the immonium function $5 \alpha$ (Scheme VI) to yield an oxygen-reactive 1,5-dihydro(iso)alloxazine analogue.

In the present case such an intermediate could be observed only in the case of model 1 , when reduction was carried out with a $\mathrm{H}_{2}$ /platinum catalyst, which leads to full hydrogenation of the $\mathrm{N}(5)-\mathrm{C}(6)$ bridge (S. Ghisla and M. Janda, unpublished experiments). In the case of model compounds 1 and 3 (X $=\mathrm{H})($ Scheme VI), the intermediate cation deprotonates to 
Scheme VI: Proposed Sequence of Borohydride Reduction, Oxygen Reoxidation, and Ring Opening of Pink Flavin and of Model Compounds

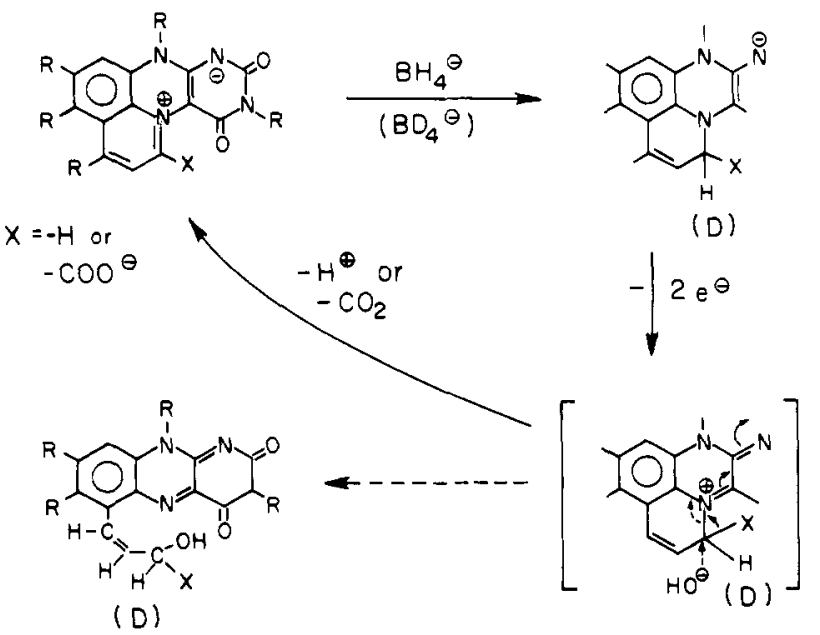

yield starting material. When the reduction is carried out aerobically with $\mathrm{BD}_{4}^{-}$, the isotope selection involved with this deprotonation step (following oxidation) leads to selective deuterium enrichment in position $5 \alpha$ (Table II). The results obtained upon reduction of pink FMN with borohydride can similarly be explained by assuming that the cationic intermediate can stabilize itself by three different competing pathways (Scheme VI): (a) proton abstraction to re-form pink starting material; (b) decarboxylation to form a "decarboxylated" starting material; (c) addition of $\mathrm{OH}^{-}$to position $5 \alpha$ to form a 6-substituted oxidized flavin chromophore (Scheme VI; $\mathrm{X}=-\mathrm{COO}^{-}$or $\mathrm{H}$ ). The $\mathrm{BH}_{4}{ }^{-}$reduction of pink FMN was carried out under aerobic conditions (cf. Materials and Methods); this reduction $-\mathrm{O}_{2}$ reoxidation process will thus have undergone several cycles. If the carboxylate group would have been at position $5 \gamma$, a decarboxylation reaction could not have occurred under such conditions. That $\mathrm{OH}^{-}$addition is found with the FMN derivative, and not to a detectable extent with the model compounds 1 and $\mathbf{3}$, is not entirely surprising, as a similar dependence of the reoxidation course on the nature of the $\mathrm{N}(5)$ substituent was found with lumiflavin models (Ghisla et al., 1971).

On comparing the structure of the covalent adducts of $\alpha \mathrm{HB}$ with L-lactate oxidase [4a,5-cyclic adduct; Ghisla et al. (1976) and Schonbrunn et al. (1976)] and D-lactate dehydrogenase (Scheme IV), it is evident that $\mathrm{L}-\alpha \mathrm{HB}$ and $\mathrm{D}-\alpha \mathrm{HB}$ bind to the two enzyme reactive centers in a diastereotopic fashion with respect to the flavin coenzyme. All evidence presently available indicates that these two enzymes work by very similar mechanisms. Thus, the geometry of the active-center functional groups should also be similar. Therefore, the hypothesis put forward in the introduction, and elsewhere (Ghisla et al., 1979), that in both cases the same flavin (Si) face is reacting with substrate seems reasonable [see Ghisla et al. (1979) for further discussion]. This would also support the hypothesis of conservation of the basic active-center geometry for these enzymes during evolution, protein modifications serving primarily to govern the substrate specificity.

\section{Acknowledgments}

We thank Dr. E. Daltrozzo for preliminary calculations of the electronic spectra of the pink flavin chromophore, E. Krienitz for recording the NMR spectra of the model compounds, M. Janda for help in the synthesis of the model compounds, M. Sappelt for skillful technical assistance, and
Dr. P. Hemmerich for valuable discussions. We also thank Professor W. Pfleiderer for a generous gift of 4,5-dichloropyrimidines.

\section{References}

Badger, G. M., Ennis, B. C., \& Matthews, W. E. (1963) Aust. J. Chem. 16, 828

Bruice, T. C. (1976) Prog. Bioorg. Chem. 4, 1-87.

Chuang, H. Y., Patek, D. R., \& Hellerman, L. (1974) J. Biol. Chem. 249, 2381-2384.

Cromartie, T. H., \& Walsh, C. T. (1975) Biochemistry 14, 3482-3490.

Deiss, H. (1965) Ph.D. Thesis, University of Stuttgart.

Dudley, K. H., Ehrenberg, A., Hemmerich, P., \& Müller, F. (1964) Helv. Chim. Acta 47, 1354.

Gaertner, B., Hemmerich, P., \& Zeller, E. A. (1976) Eur. J. Biochem. 63, 211-221.

Ghisla, S., Hemmerich, P., \& Jefcoate, C. (1972) J. Chem. Soc., Perkin Trans. 1, 1564-1569.

Ghisla, S., Hartman, V., Hemmerich, P., \& Müller, F. (1973) Justus Liebigs Ann. Chem. 1973, 1388-1415.

Ghisla, S., Lhoste, J. M., Olson, S., Whitfield, C. D., \& Massey, V. (1979) in Proceedings of the VIIth Symposium on Flavins and Flavoproteins (in press).

Ghisla, S., \& Massey, V. (1978) in Mechanisms of Oxidizing Enzymes (Singer, T. P., \& Ondarza, R., Eds.) pp 55-68, Elsevier/North-Holland, New York.

Ghisla, S., Tauscher, L., \& Hemmerich, P. (1971) Chimia 25.

Ghisla, S., Massey, V., Lhoste, J. M., \& Mayhew, S. G. (1974) Biochemistry 13, 589-597.

Ghisla, S., Ogata, H., Massey, V., Schonbrunn, A., Abeles, R. H., \& Walsh, C. T. (1976) Biochemistry 15, 1791-1797.

Hevesi, L., \& Bruice, T. C. (1973) Biochemistry 12, 290.

Horiike, K., Hishina, Y., Miyake, Y., \& Yamano, T. (1975) J. Biochem. (Tokyo) 78, 57.

Jewess, P. J., Kerr, M. W., \& Whitaker, D. P. (1975) FEBS Lett. 53, 292-296.

Lederer, F. (1974) Eur. J. Biochem. 46, 393-399.

Mager, H. I., \& Berends, W. (1976) Tetrahedron 32, 2303.

Marcotte, P., \& Walsh, C. T. (1976) Biochemistry 15, 3070-3076.

Massey, V., \& Ghisla, S. (1975) Fed. Eur. Biochem. Soc. Meet., Proc. 40, 145-158.

Maycock, A. L., Abeles, R. H., Salach, J. I., \& Singer, T. P. (1976) Biochemistry 15, 114.

Mayhew, S. G. (1971) Biochim. Biophys. Acta 235, 289.

Mayhew, S. G., \& Massey, V. (1969) J. Biol. Chem. 244, 794.

Mayhew, S. G., \& Strating, M. J. J. (1975) Eur. J. Biochem. $59,539$.

Mayhew, S. G., Whitfield, C., Ghisla, S., \& Schuman-Jorns, M. (1974) Eur. J. Biochem. 44, 579.

Olson, S. T., Massey, V., Ghisla, S., \& Whitfield, C. D. (1979) Biochemistry (second of three papers in this issue).

Porter, D. J. T., Voet, J. G., \& Bright, H. J. (1973) J. Biol. Chem. 248, 4400.

Ronchi, S., Minchiotti, L., Galliano, M., Curti, B., \& Ghisla, S. (1979) in Proceedings of the VIIth Symposium on Flavins and Flavoproteins (in press).

Roth, R., \& Erlenmeyer, H. (1954) Helv. Chim. Acta 37, 1064-1068.

Schoellnhammer, G., \& Hemmerich, P. (1974) Eur. J. Biochem. 44, 561.

Schonbrunn, A., Abeles, R. H., Walsh, C. T., Ghisla, S., Ogata, H., \& Massey, V. (1976) Biochemistry 15, 1798-1807. 
Scola-Nagelschneider, G., \& Hemmerich, P. (1976) Eur. J. Biochem. 66, 567.

Walker, W., Hemmerich, P., \& Massey, V. (1970) Eur. J. Biochem. 13, 258.

Walsh, C. T. (1977) Horiz. Biochem. Biophys. 3, 36.
Walsh, C. T. (1978) Annu. Rev. Biochem., 881.

Walsh, C. T., Abeles, R. H., \& Kaback, H. R. (1972) J. Biol. Chem. 247, 7858-7863.

Yon, K., Arnold, L., \& Kaplan, N. (1977) Arch. Biochem. Biophys. 180,550 